\title{
CARDIOVASCULAR TESTING OF SEASICKNESS IN HEALTHY VOLUNTEERS ON LIFE RAFTS
}

\author{
ANDRZEJ MOLISZ ${ }^{1}$, MAŁGORZATA RYK ${ }^{1}$, MICHAŁ RATAJ ${ }^{2}$, BARBARA KOŁACZYŃSKA², \\ KATARZYNA NOWICKA-SAUER ${ }^{1}$, TOMASZ PRZEWOŹNY ${ }^{3}$, MARTA SAUER ${ }^{4}$, PIOTR GUTKNECHT ${ }^{1}$, \\ BARTOSZ TRZECIAK ${ }^{1}$, and JANUSZ SIEBERT ${ }^{1}$
}

${ }^{1}$ Medical University of Gdańsk, Gdańsk, Poland
Department of Family Medicine
${ }^{2}$ Gdynia Maritime University, Gdynia, Poland
Scientific Circle "Seaways," Faculty of Navigation
${ }^{3}$ Medical University of Gdańsk, Gdańsk, Poland
Department of Otolaryngology
${ }^{4}$ Gdańsk University of Technology, Gdańsk, Poland
Scientific Circle "Materials in Medicine," Faculty of Mechanical Engineering

\begin{abstract}
Objectives: The role of the cardiovascular system in the development of seasickness remains uncertain. Material and Methods: Overall, 18 healthy students (10 males and 8 females) aged 18-24 years volunteered in the project, spending 2-7 h on life rafts. The cardiovascular system was examined with impedance cardiography. Susceptibility and symptoms of seasickness were evaluated by the Motion Sickness Susceptibility Questionnaire Shortform (MSSQ-Short) and the Motion Sickness Assessment Questionnaire (MSAQ). The Visual Analogue Scale (VAS), ranging 0-10, was used to assess nausea, dizziness and mood. The parameters were assessed at 2 time points. Results: Differences in the heart rate (HR), the thoracic fluid content index (TFCI), the stroke index (SI) and the Heather index (HI) before launching the life rafts and after leaving them were observed (78.6, 20.8, 55.6 and 15.9 vs. $70.1,19.7,60.5$ and 17.9, with p-values of $0.002,<0.001,0.003$ and 0.004 , respectively). Females reacted with changes in SI and HR more vividly, whereas males regulated more HI and TFCI. In addition, HR correlated significantly with the central and peripheral symptoms in MSAQ, stroke volume (SV) with peripheral and sopite-related ones, SI with overall ones, and pulse pressure with overall, gastrointestinal and central ones (Spearman's rank correlation coefficient [ $[0$ ] was $-0.478,-0.711,0.476,0.472,0.525,-0.476,-0.579$ and -0.584 , respectively). As regards MSSQ-Short, it correlated negatively with sopite-related symptoms in MSAQ $(\mathrm{Q}=-0.486)$. Mood in VAS correlated significantly with gastrointestinal symptoms, SI and the cardiac index $(\mathrm{CI})(\varrho=-0.752,-0.492$ and -0.489 , respectively). Conclusions: It was found that HR correlated negatively, and SV/SI correlated positively, with the severity of seasickness symptoms measured with MSAQ. Gender is probably an independent factor influencing reactions to motion. Women react with SI increase whereas men react with increased heart contractility (HI rise). Negative mood in seasickness evaluated with VAS seems to be mostly determined by gastrointestinal symptoms assessed with MSAQ and diminished cardiovascular indices (both CI and SI). Int J Occup Med Environ Health. 2020;33(4):467-77
\end{abstract}

Key words:

survival, impedance cardiography, seasickness, life rafts, MSAQ, MSSQ

Received: January 10, 2019. Accepted: March 9, 2020.

Corresponding author: Andrzej Molisz, Medical University of Gdańsk, Department of Family Medicine, Dębinki 2, 80-211 Gdańsk, Poland (e-mail: amol@gumed.edu.pl). 


\section{INTRODUCTION}

Seasickness is the most dramatic form of motion sickness (MS) $[1,2]$. The aetiology of seasickness is based on the repetitive linear or angular acceleration of the head with an emphasis on the vertical linear acceleration or heave [2]. This common physiological response to unnatural motion stimuli occurs as a feeling of unwellness. Sopite syndrome alongside autonomic reactions like sweating, hypersalivation, nausea, vomiting and pallor constitute the main symptoms of MS [3,4]. What is more, MS indicates peripheral vasodilation that leads to hypothermia [3].

Sopite syndrome is characterized mostly by drowsiness, mood changes, boredom, apathy, failure of initiative, increased irritability and even changes in personality, unaccompanied by other symptoms of MS [4,5]. It usually appears before nausea and persists for up to a few days after nausea has abated. It can also constitute the only reaction to motion. The duration of this syndrome relates to the length of exposure and intensity of motion stimulation [5]. Drowsiness, the cardinal symptom of MS, manifests itself with frequent yawning, naps and sleeping longer than usual.

The heredity of MS susceptibility is estimated at around $57-70 \%$, and involves genetic and epigenetic regulation on genes. The prediction of individual MS susceptibility is still impossible because of the lack of any objective parameters with high enough sensitivity and specificity $[1,2]$. The development of MS depends on individual, psychological and physiological features such as race, age (with a peak between the age of 3 and 12, subsequent stabilization and decrease at $>65$ years of age), gender (women are more susceptible than men, especially during menstruation or pregnancy) and athleticism (which correlates with higher MS susceptibility owing to increased vasomotor activity) $[2,6,7]$. What is more, symptoms are believed to rise due to high frequency of meals in previous $24 \mathrm{~h}$ [3]. Sleep deprivation was reported to increase MS susceptibility $[5,8]$.
The aetiology of MS is still somewhat unclear. The most popular and widely accepted theory of its development is the neural mismatch theory. The sensory conflict appears when the actual signals from the eyes, semicircular canals, otoliths and the somatosensory system mismatch the internal model formed under past experience [1,9].

The stimulation of a well-functioning vestibular apparatus is crucial for the appearance of MS. The susceptibility to MS is related to the strength of vestibular reaction [1,2]. Subjects suffering from vestibular migraine and Ménière's disease, especially females, show increased sensitivity to motion $[3,7,10]$. In almost half of children and two-thirds of adults with migraine, the disease is accompanied by MS. Although the exact mechanism of this connection is not certain, decreased brain levels of serotoninergic activity link MS to migraine [2]. Interesting observations have also been made about the asymmetry in otolith function and a wrong perception of the true vertical as possible causes of MS [2,11,12].

Vestibulo-sympathetic activity associated with changes in the body orientation regulates cardiovascular function and respiration $[3,5,13]$. An inappropriate activation of the vestibulo-cardiovascular reflex leads to the appearance of MS [9], an increase in HR and cardiac output [7]. The heart rate can be used as an indicator of MS. Its increase is correlated with the development of unwellness [14], and is influenced by nausea and stress response [9]. Parasympathetic activity decreases during MS and can persist longer than the duration of MS inducing factors [2].

Motion sickness is a common factor negatively influencing performance at sea in seamen, fishermen, sailors etc. [15-17]. Since habituation reduces the symptoms, a question arises whether this process can be accelerated. Prophylaxis is beneficial for managing MS symptoms [17]. The most effective MS prophylaxis are anticholinergics and antihistamines, followed by visual-vestibular habituation training $[17,18]$. To alleviate MS symptoms, it is also helpful to take vitamin $\mathrm{C}$, to control breathing or to focus 
vision on the distant horizon [3]. In addition, psychological features such as self-efficacy were reported as important modifiable factors influencing seasickness susceptibility [19].

\section{Aim of the study}

The aim was to find cardiovascular parameters which change in subjects undergoing motion, and to indicate these which correlate with the severity of the symptoms. The secondary aim was to find correlations between the symptoms of seasickness and MS susceptibility.

\section{MATERIAL AND METHODS}

The presented research is part of a project called Life Rafts Survival Tests designed and led by the Gdynia Maritime University in cooperation with the Medical Univer-

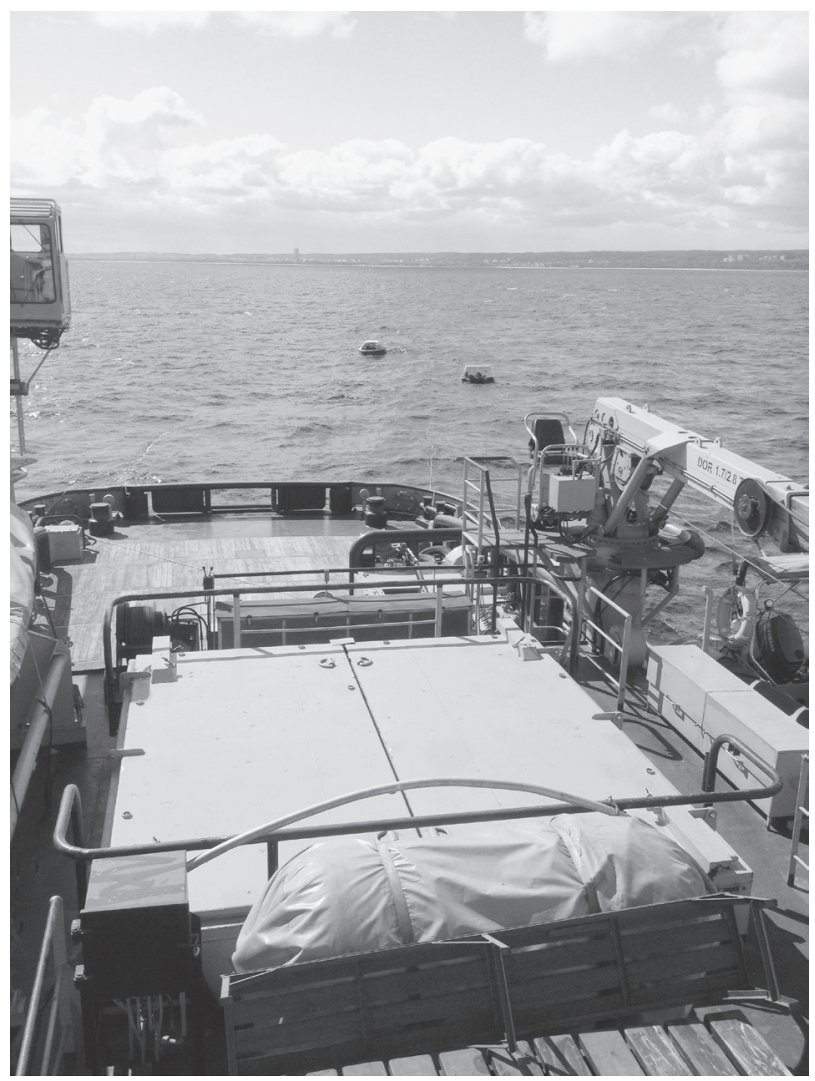

Figure 1. Life rafts connected to the ship with long painter lines sity of Gdansk, Poland. Overall, 18 healthy subjects (students from the Gdynia Maritime University and the Polish Naval Academy) volunteered in the project. The group comprised of 10 males and 8 females aged 18-24 years (the mean age was $20.5 \pm 1.5$ in the whole group, with $21.1 \pm 1.5$ in males and $19.8 \pm 1.2$ in females). All the participants were delivered to Gdansk Bay on board a search and rescue (SAR) ship. Two life rafts were inflated on board the ship and launched subsequently. For safety reasons, the life rafts (each of 10 subjects capacity) were connected to a ship with long painter lines for the whole testing (Figure 1). The life rafts were equipped according to the International Convention for the Safety of Life at Sea (SOLAS). One of the life rafts was open at the ship deck to present the equipment and procedures to all the participants (Figure 2). The subjects were divided into

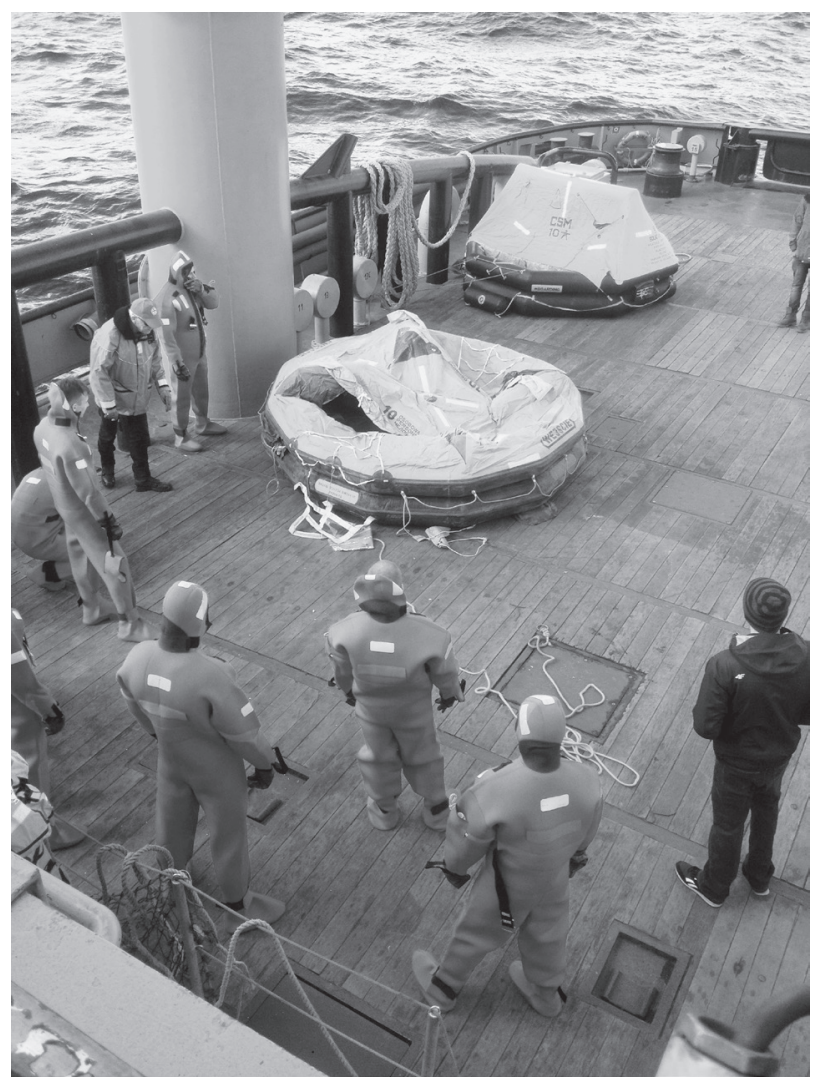

Figure 2. Participants and life rafts on board the search and rescue (SAR) ship in Gdańsk Bay, Poland, April 2017 
male and female rafts. All the subjects were dressed in immersion suits (Figure 2). The volunteers spent 2-7 h on the life rafts. The criterion for the end of participation was the participant's discomfort (e.g., nausea, vomiting, cold). The life rafts were communicated with the ship with a very high-frequency system; thus, the subjects were evacuated individually by the ship's crew immediately after a call.

The examinations were performed on board a SAR vessel $\mathrm{m} / \mathrm{s}$ Kapitan Poinc. Its length is $49.8 \mathrm{~m}$, width $13.6 \mathrm{~m}$, drought $4.6 \mathrm{~m}$, engines $2 \times 1920 \mathrm{hp}$, max speed $13 \mathrm{kn}$, basic crew 11 persons, ice class L1, and it can pick up 272 survivors. During the execution of the research, air temperature was $13^{\circ} \mathrm{C}$, water temperature $8^{\circ} \mathrm{C}$, and wind speed $3-4$ in the Beaufort scale.

\section{Protocol}

The study protocol included questionnaires and an examination of the cardiovascular system. The tests were performed at 2 time points (TPs): TP1 before launching the life rafts and TP2 immediately after leaving the life rafts (both on board the ship).

Before launching the life rafts (at TP1), the initial parameters were tested. Susceptibility to seasickness was evaluated with the Motion Sickness Susceptibility Questionnaire Short-form (MSSQ-Short) [20]. The MSSQ raw score, susceptibility in childhood (MSA) and susceptibility in adulthood (MSB) were calculated [20]. The intensity of nausea, dizziness and mood were evaluated with the $100 \mathrm{~mm}$ Visual Analogue Scale (VAS) with anchors $0-10$ pts [21,22]. Higher scores indicated a higher intensity of the assessed symptom. Cardiovascular parameters such as the heart rate (HR), systolic, diastolic and mean blood pressure $\left(\mathrm{BP}_{\text {sys }}, \mathrm{BP}_{\text {dia }}\right.$ and $\mathrm{MAP}$, respectively), the thoracic fluid content index (TFCI), stroke volume (SV), the stroke index (SI), the cardiac index (CI), the velocity index (VI), the acceleration index (ACI), the Heather index (HI), the systemic vascular resistance index (SVRI) and pulse pressure (PP) were evaluated with impedance cardiography (ICG). Also, a 10-min supine resting test was performed.

Immediately after leaving the life rafts (at TP2), impedance cardiography alongside the Motion Sickness Assessment Questionnaire (MSAQ), created by Gianaros et al. [23] to assess overall, gastrointestinal, central, peripheral and sopite-related symptoms of MS, were performed. Additionally, the intensity of nausea, dizziness and mood were evaluated with VAS.

\section{Statistical analysis}

Statistica 12 by StatSoft (Tulsa, Oklahoma, USA) was used for statistical analysis. Normality was evaluated by the Shapiro-Wilk test. The variability of cardiovascular indices between TP1 and TP2 was assessed with Student's t-test for dependent samples and the Wilcoxon signed-rank test. Spearman's rank correlation coefficient was calculated for correlations between cardiovascular indices and MSAQ. A second-degree polynomial regression analysis was performed to assess the significance of the nonlinear association between cardiovascular indices and MSAQ (all at TP2), and to create best-fit curves for these relations. Details concerning the tests used are specified in the tables' legends.

\section{RESULTS}

Several observations have been made in questionnaires and cardiovascular indices. For the parameters used in the text, please look at the list of abbreviations.

\section{Cardiovascular parameters variability}

Statistically significant differences have been observed in cardiovascular indices at TP1 and TP2. The results are presented in Table 1.

\section{Gender differences in cardiovascular response}

Some observations have been made in the groups divided by gender. Females reacted with changes in SI and HR more vividly, whereas males regulated more HI and TFCI. 
Table 1. Cardiovascular parameters measured with impedance cardiography on 18 participants at 2 time points: 1 - before launching the life rafts and 2 - immediately after leaving the life rafts (both on board the ship), study conducted in Gdańsk Bay, Poland, April 2017

\begin{tabular}{lccc}
\hline \multirow{2}{*}{ Parameter } & \multicolumn{2}{c}{ Time point } & \\
\cline { 2 - 3 } & 1 & 2 & $\mathrm{p}$ \\
\hline $\mathrm{ACI}$ & 125.7 & 122.7 & $0.372^{\mathrm{a}}$ \\
$\mathrm{BP}_{\text {dia }}$ & 73.7 & 74.2 & $0.768^{\mathrm{b}}$ \\
$\mathrm{BP}_{\text {sys }}$ & 123.6 & 123.5 & $0.973^{\mathrm{b}}$ \\
$\mathrm{CI}$ & 4.3 & 4.2 & $0.230^{\mathrm{b}}$ \\
$\mathrm{HI}$ & $\mathbf{1 5 . 9}$ & $\mathbf{1 7 . 9}$ & $\mathbf{0 . 0 0 4}^{\mathrm{a}}$ \\
$\mathrm{HR}$ & $\mathbf{7 8 . 6}$ & $\mathbf{7 0 . 1}$ & $\mathbf{0 . 0 0 2}^{\mathrm{b}}$ \\
MAP & 85.2 & 85.6 & $0.863^{\mathrm{b}}$ \\
$\mathrm{SI}$ & $\mathbf{5 5 . 6}$ & $\mathbf{6 0 . 5}$ & $\mathbf{0 . 0 0 3}^{\mathrm{b}}$ \\
SVRI & 1505.0 & 1567.1 & $0.145^{\mathrm{b}}$ \\
TFCI & $\mathbf{2 0 . 8}$ & $\mathbf{1 9 . 7}$ & $<\mathbf{0 . 0 0 1}^{\mathrm{b}}$ \\
VI & 74.4 & 76.9 & $0.064^{\mathrm{a}}$ \\
\hline
\end{tabular}

$\mathrm{ACI}$ - acceleration index; $\mathrm{BP}_{\mathrm{dia}}$ - diastolic blood pressure;

$\mathrm{BP}_{\text {sys }}$ - systolic blood pressure; CI - cardiac index; HI - Heather index; HR - heart rate; MAP - mean arterial pressure; SI - stroke index;

SVRI - systemic vascular resistance index; TFCI - thoracic fluid content index; VI - velocity index.

Bolded are statistically significant differences $(p<0.05)$.

${ }^{a}$ Median values and Wilcoxon signed-rank test results are presented.

${ }^{\mathrm{b}}$ Parameters with normal distribution - mean values and results of

Student's t-test are presented.

The other indices had similar trends in the gender groups as in the whole group. These observations are presented in Table 2.

\section{Associations between cardiovascular indices}

and seasickness symptoms

The intensity of seasickness evaluated with MSAQ significantly correlated with several cardiovascular parameters at TP2. This was observed both for the overall result of MSAQ and its constituent subscales (gastrointestinal, central, peripheral and sopite-related). The results are presented in Table 3. There was hardly any correlation of such type at TP1 (before launching the life rafts).
Table 2. Cardiovascular parameters in gender groups measured with impedance cardiography on 18 participants at 2 time points: 1 - before launching the life rafts and 2 - immediately after leaving the life rafts (both on board the ship), study conducted in Gdańsk Bay, Poland, April 2017

\begin{tabular}{lcccc}
\hline \multirow{3}{*}{ Parameter } & \multicolumn{3}{c}{ Time point } & \multirow{2}{*}{$\mathrm{p}$} \\
\cline { 2 - 4 } & 1 & 2 & $\Delta$ & \\
\hline Females & & & & \\
HI & 20.6 & 21.3 & 0.7 & $0.263^{\text {a }}$ \\
HR & $\mathbf{8 0 . 0}$ & $\mathbf{6 9 . 6}$ & $\mathbf{- 1 0 . 4}$ & $\mathbf{0 . 0 2 5}^{\text {b }}$ \\
SI & $\mathbf{5 8 . 8}$ & $\mathbf{6 5 . 2}$ & $\mathbf{6 . 4}$ & $\mathbf{0 . 0 1 3}^{\text {b }}$ \\
TFCI & 17.7 & 17.2 & -0.5 & $0.069^{\text {a }}$ \\
Males & & & & \\
HI & $\mathbf{1 3 . 0}$ & $\mathbf{1 5 . 3}$ & $\mathbf{2 . 3}$ & $\mathbf{0 . 0 0 7}^{\text {a }}$ \\
HR & $\mathbf{7 7 . 5}$ & $\mathbf{7 0 . 6}$ & $\mathbf{- 6 . 9}$ & $\mathbf{0 . 0 4 9}^{\text {b }}$ \\
SI & 53.0 & 56.8 & 3.8 & $0.108^{b}$ \\
TFCI & $\mathbf{2 1 . 5}$ & $\mathbf{2 0 . 7}$ & $\mathbf{- 0 . 8}$ & $\mathbf{0 . 0 0 5}^{\text {a }}$ \\
\hline
\end{tabular}

Abbreviations and explanations as in Table 1.

For further statistical assessment of the relations between objective (ICG) and subjective (MSAQ) observations, a regression analysis was employed. From all created models, only the polynomial regression analysis for $\mathrm{BP}_{\text {sys }}$ was statistically significant. In this analysis, the variability of MSAQ overall result was explained by the variability of $\mathrm{BP}_{\text {sys }}$ and $\mathrm{BP}_{\text {sys }}{ }^{2}$ according to the polynomial regression equation:

$$
\text { MSAQ }=b_{0}+b_{1} \times \mathrm{BP}_{\text {sys }}+b_{2} \times \mathrm{BP}_{\text {sys }}{ }^{2}
$$

The results are presented in Table 4 and Figure 3.

\section{Motion sickness susceptibility}

Among MS symptoms, the MSSQ raw score and MSB correlated only with sopite-related symptoms in MSAQ at TP2 ( $\varrho=-0.486, \varrho=-0.584$, respectively). Among cardiovascular indices, the MSSQ raw score, MSA and MSB correlated significantly with SVRI at TP2 $(\varrho=-0.606, \varrho=$ $-0.610, \varrho=-0.526$, respectively). 
Table 3. Correlation between the results of the Motion Sickness Assessment Questionnaire (MSAQ) and cardiovascular parameters from impedance cardiography on 18 participants at time point 2 - on board the ship immediately after leaving the life rafts, a study conducted in Gdańsk Bay, Poland, April 2017

\begin{tabular}{lccccc}
\hline \multirow{2}{*}{$\begin{array}{c}\text { Impedance } \\
\text { cardiography } \\
\text { parameter }\end{array}$} & \multicolumn{5}{c}{ MSAQ subscale score } \\
\cline { 2 - 6 } & overall & gastrointestinal & central & peripheral & sopite-related \\
\hline $\mathrm{ACI}$ & 0.072 & 0.363 & 0.243 & -0.075 & -0.184 \\
$\mathrm{BP}_{\text {dia }}$ & 0.299 & 0.173 & 0.283 & 0.140 & 0.286 \\
$\mathrm{BP}_{\text {sys }}$ & -0.354 & -0.370 & $\mathbf{- 0 . 5 3 2}$ & 0.100 & 0.258 \\
$\mathrm{CI}$ & 0.411 & 0.305 & 0.180 & -0.113 & 0.335 \\
$\mathrm{HI}$ & 0.317 & 0.396 & 0.292 & -0.455 & 0.013 \\
$\mathrm{HR}$ & -0.273 & -0.249 & $\mathbf{- 0 . 4 7 8}$ & $\mathbf{- 0 . 7 1 1}$ & -0.060 \\
MAP & 0.184 & 0.101 & 0.113 & 0.189 & 0.308 \\
PP & $\mathbf{0 . 4 7 6}$ & $\mathbf{- 0 . 5 7 9}$ & $\mathbf{- 0 . 5 8 4}$ & -0.008 & 0.117 \\
SI & $\mathbf{0 . 5 2 5}$ & 0.347 & 0.419 & 0.365 & 0.370 \\
SV & 0.369 & 0.074 & 0.205 & $\mathbf{0 . 4 7 6}$ & $\mathbf{0 . 4 7 2}$ \\
SVRI & -0.176 & -0.167 & -0.082 & 0.442 & -0.006 \\
TFCI & -0.253 & 0.200 & -0.203 & -0.073 & -0.363 \\
VI & 0.091 & 0.381 & 0.216 & -0.199 & -0.161 \\
\hline
\end{tabular}

$\mathrm{PP}$ - pulse pressure; SV - stroke volume.

Spearman's rank correlation coefficient is presented.

Other abbreviations and explanations as in Table 1.

Table 4. Coefficients resulting from the regression analysis (data on 18 participants at time point 2 - on board the ship immediately after leaving the life rafts), a study conducted in Gdańsk Bay, Poland, April 2017

\begin{tabular}{lccccc}
\hline \multicolumn{1}{r}{ Variable } & $\mathrm{b}$ & $\mathrm{SE}$ & $\begin{array}{c}\mathrm{p} \\
\text { (variable) }\end{array}$ & $\mathrm{R}^{2}$ & $\begin{array}{c}\mathrm{p} \\
\text { (estimation) }\end{array}$ \\
\hline Constant term & $\mathbf{8 0 4 . 5 8 3}$ & $\mathbf{2 4 6 . 6 8 8}$ & $\mathbf{0 . 0 0 5}$ & $\mathbf{0 . 4 3 1}$ & $\mathbf{0 . 0 1 5}$ \\
$\mathrm{BP}_{\text {sys }}$ & $-\mathbf{1 1 . 9 5 4}$ & $\mathbf{3 . 8 4 5}$ & $\mathbf{0 . 0 0 7}$ & $\mathbf{0 . 4 3 1}$ & $\mathbf{0 . 0 1 5}$ \\
$\mathrm{BP}_{\text {sys }}{ }^{2}$ & $\mathbf{0 . 0 4 5}$ & $\mathbf{0 . 0 1 5}$ & $\mathbf{0 . 0 0 8}$ & $\mathbf{0 . 4 3 1}$ & $\mathbf{0 . 0 1 5}$ \\
\hline
\end{tabular}

b - unstandardized regression coefficient.

Bolded are statistically significant results.

Other abbreviations and explanations as in Table 1.

\section{VAS observations}

Few statistically significant correlations between the VAS results and MSAQ were observed. At TP2, the MSAQ raw score correlated with VAS-nausea and VAS-mood ( $\mathrm{Q}=$ $0.654, \varrho=-0.725$, respectively). Similar correlations were observed in gastrointestinal symptoms $(\varrho=0.872, \varrho=$
-0.752 , respectively), whereas central symptoms correlated with VAS-dizziness $(\varrho=0.652)$. At TP1, no significant correlations were observed.

Very few correlations between cardiovascular ICG parameters measured at the 2 time points and the VAS results were observed. At TP2, VAS-mood correlated negatively 


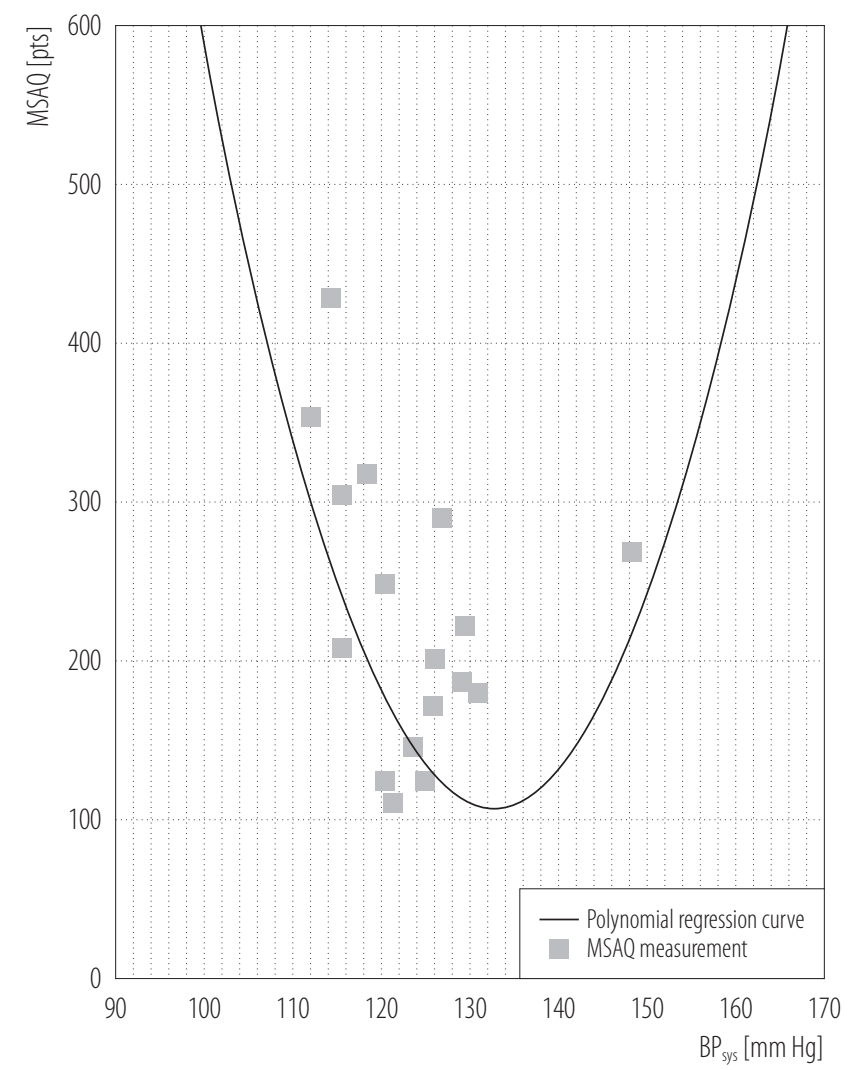

Figure 3. Polynomial regression curve of systolic blood pressure $\left(\mathrm{BP}_{\text {sys }}\right)$ against the Motion Sickness Assessment Questionnaire (MSAQ) (data on 18 participants at time point 2 on board the ship immediately after leaving the life rafts), a study conducted in Gdańsk Bay, Poland, April 2017

with SI $(\varrho=-0.492)$ and CI $(\varrho=-0.489)$, and VAS-nausea correlated with PP $(\varrho=-0.517)$. There were no significant correlations with VAS-dizziness at this time point. At TP1, the only significant correlation was between VAS-dizziness and $\mathrm{HI}(\varrho=-0.502)$.

\section{DISCUSSION}

\section{Cardiovascular parameters variability}

Cardiovascular changes in subjects with seasickness were previously reported $[5,9,13,14]$. Heart rate variability was used to diagnose and evaluate this disease. In this research, the authors planned to analyze numerous cardiovascular parameters which might be useful in assessing seasickness. The vestibular system has been shown to play an important role in HR and respiratory regulation [5,13]. Its aim is to ensure sufficient circulation and respiration during body movements. Questions arise which hemodynamic indices are affected by changes in the body position, and whether cardiovascular response to motion differs in patients with and without the symptoms of seasickness.

The heart rate was reported to rise concurrently with nausea [14]. Yates et al. [24] observed increased HR due to linear acceleration in healthy subjects. A similar pattern was observed in $\mathrm{BP}_{\text {sys }}$ [24]. These changes lasted for only a few seconds after the stimulus disappeared. Probably due to this fact, no such reactions were observed in this research. Owing to the technical difficulties in performing ICG on the life rafts, the authors examined the subjects only immediately after boarding the ship again. Both in males and in females, a statistically significant decrease in HR following the abandonment of the life rafts was observed. This might relate to stress before starting the experiment and its release afterwards. Neither systolic nor diastolic blood pressure changed after leaving the life rafts.

\section{Gender differences in cardiovascular response}

Some differences were observed in hemodynamic indices between males and females. Both groups had similar CI at TP1 and TP2. Consequently, having decreased HR, they must have had some changes in other hemodynamic indices. Females reacted more vividly with SI increase whereas males had increased HI, which is an indicator of heart contractility. Additionally, in males TFCI declined significantly at TP2. Gender differences in response to autonomic stimulation were reported before [25-29]. Higher HR at rest in women than in men was a common observation [25,30]. Many authors reported higher sympathovagal balance in men compared to women, which was due to higher sympathetic and lower parasympathetic tone $[27,30,31]$. However, it was shown that females reacted to watching negative threat-related movies more 
emotionally, with increased sympathetic activity resulting in higher HR [29], whereas sympathetic reactivity in males was not so pronounced and they presented with increased parasympathetic reactivity resulting in decreased HR. Similar reactions were observed to trigeminal nerve stimulation [28], although in the second research, stable HR was reported in females.

Some observations were also made for CO and SV. Dry static apnea in experienced divers caused $\mathrm{CO}$ and SV drops, accompanied by SVR rise, which were more pronounced in females [26]. Similar observations were made in the head-up tilt test compared to supine position [27]. Trigeminal nerve stimulation during a cycling exercise caused SV increase only in women with stable CO in both groups [28], which seems congruent with this study.

\section{Associations between cardiovascular indices and seasickness symptoms}

The observation of correlations between cardiovascular indices and MSAQ is worth analyzing. No correlations at TP1 and a few significant correlations at TP2 support the possible connection of these findings with seasickness. The heart rate, decreasing between TP1 and TP2 both in females and males, correlated negatively with peripheral and central symptoms of seasickness. This could be connected with the authors' finding of HR decrease after leaving the life rafts, which would suggest that seasickness could cause HR drop. On the contrary, a significant positive correlation between HR and the subjective severity of seasickness was reported [14]. The authors are not sure why their observations seem to be opposite. There is no relationship between CI and MSAQ; thus, not surprisingly, there is a positive correlation between SV/SI and some of the MSAQ results (a rise in SV/SI results in HR decrease to stabilize CI).

The polynomial regression analysis of $\mathrm{BP}_{\text {sys }}$ against MSAQ revealed a significant nonlinear trend. It could also determine whether an optimum $\mathrm{BP}_{\text {sys }}$ existed. Figure 3 shows that the lowest MSAQ overall results are obtained for $\mathrm{BP}_{\text {sys' }}$ ranging 130-135 (a high normal blood pressure). It could be hypothesized that subjects with lower and higher blood pressure tend to have more seasickness symptoms. The correlation analysis revealed a significant negative correlation between $\mathrm{BP}_{\text {sys }}$ and MSAQ central symptoms. The ascending limb of the parabola might be strongly influenced by the outlier $\left(\mathrm{BP}_{\mathrm{sys}}=148\right)$. This is a single high observation; however, it should not be treated as an experimental error since it results from a 10-min test and the final value is the average. Javaid et al. reported significantly lower mean arterial pressure in subjects reporting nausea as a MS symptom [32], which might be congruent with these results (however, the authors of this research did not observe any significant differences either in the mean or diastolic blood pressure).

A question arises whether the observed negative correlation also relates to higher blood pressure values. In this context, extending the study population with subjects presenting a wider arterial blood pressure range seems especially interesting. As discussed above, no statistically significant difference in $\mathrm{BP}_{\text {sys }}$, measured at TP1 and TP2, was observed, which might suggest that the variability of MSAQ is explained by the average personal value of $\mathrm{BP}_{\text {sys }}$, and not by its temporary value due to MS.

\section{Motion sickness susceptibility}

The MSSQ results were reported to have a predictive value in vestibular impairment due to concussion after sport activity [33]. In this research, it was difficult to predict the results in MSAQ or VAS on the basis of MSSQShort. The MSSQ raw score and MSB correlated negatively with sopite-related symptoms at TP2. This might suggest that subjects who are more susceptible to MS have fewer symptoms of sopite syndrome.

Sopite syndrome is defined as drowsiness, fatigue and emotional lability due to motion. It is treated as part of seasickness but could be independent of other symptoms; 
thus, it can precede them, persist after the subject's adaptation to them and exist in absence of them [4,34]. This concept might be supported by the fact that the authors have observed a negative correlation between MSSQ and sopite-related symptoms at TP2 (when the subjects were not undergoing motion anymore) whereas no other correlations between MSSQ and MSAQ at TP2 were observed. The theory of a vestibular cause of sopite syndrome derives from the fact that people who have lost their vestibular function do not suffer from sopite-related symptoms [4]. However, MSSQ-Short does not contain any questions of sopite-related symptoms but it contains questions of feeling sick and nauseated [20] which refer to gastrointestinal symptoms of seasickness according to Gianaros [23].

\section{VAS observations}

The strong negative correlation between gastrointestinal symptoms and mood in VAS at TP2 suggests that these symptoms might be the strongest determinant of negative emotions associated with seasickness. Other correlates of mood at TP2 were decreased SI and CI. A negative correlation between fatigue and these parameters was previously reported $[35,36]$. A question arises whether the negative emotions as found in this research are related to CI or symptoms of seasickness. Also, HI was reported to be negatively correlated with mood [36]. In this research, it was negatively correlated with dizziness at TP1 (before the experiment). This could suggest that subjects with a lower heart contractility owing to decreased sympathetic tone have more central symptoms even before undergoing motion.

\section{Limitations}

The study lacks an important part which would be cardiovascular testing on board the life rafts. This was impossible to perform in the given circumstances. The unstable ground and moisture in the life rafts inhibited the use of impedance cardiography. This is a preliminary report on a small group which should be a pilot study for a bigger project aiming to deliver a cardiovascular description of seasickness.

\section{CONCLUSIONS}

Several cardiovascular parameters change in subjects undergoing motion. The most important of these seem to be HR and SV/SI which correlate negatively (HR) or positively (SV/SI) with the severity of seasickness symptoms measured with MSAQ. Gender is probably an independent factor influencing reaction to motion. Women react with SI increase whereas men react with increased heart contractility (HI rise). These results seem to support the theory that sopite syndrome is an independent part of MS. Consequently, sopite-related symptoms correlate negatively with MSSQ-Short results. Negative mood in seasickness evaluated with VAS seems to be mostly determined by gastrointestinal symptoms assessed with MSAQ and diminished cardiovascular indices (CI and SI). The observations made by the authors may contribute to understanding the pathophysiological mechanisms involved in the development and persistence of MS, which could help in better treatment and prophylaxis of this disorder in people working at sea.

\section{ACKNOWLEDGMENTS}

Special thanks to the search and rescue (SAR) team from Gdynia for their assistance and the opportunity to perform the research on board their ship m/s Kapitan Poinc.

\section{REFERENCES}

1. Nachum Z, Gordon CR, Shahal B, Spitzer O, Shupak A. Active high-frequency vestibulo-ocular reflex and seasickness susceptibility. Laryngoscope. 2002;112(1):179-82, https://doi. org/10.1097/00005537-200201000-00031.

2. Shupak A, Gordon CR. Motion sickness: advances in pathogenesis, prediction, prevention, and treatment. Aviat Space Environ Med. 2006;77(12):1213-23.

3. Zhang L-L, Wang J-Q, Qi R-R, Pan L-L, Li M, Cai Y-L. Motion Sickness: Current Knowledge and Recent Advance. CNS 
Neurosci Ther. 2016;22(1):15-24, https://doi.org/10.1111/cns. 12468.

4. Lawson BD, Mead AM. The sopite syndrome revisited: Drowsiness and mood changes during real or apparent motion. Acta Astronaut. 1998;43(3-6):181-92, https://doi.org/ 10.1016/S0094-5765(98)00153-2.

5. Lackner JR. Motion sickness: more than nausea and vomiting. Exp Brain Res. 2014;232(8):2493-510, https://doi. org/10.1007/s00221-014-4008-8.

6. Lamb S, Kwok KCS. MSSQ-Short Norms May Underestimate Highly Susceptible Individuals: Updating the MSSQShort Norms. Hum Factors. 2015;57(4):622-33, https://doi. org/10.1177/0018720814555862.

7. Golding JF. Motion sickness susceptibility. Auton Neurosci. 2006;129(1-2):67-76, https://doi.org/10.1016/j.autneu.2006. 07.019.

8. Kaplan J, Ventura J, Bakshi A, Pierobon A, Lackner JR, DiZio $P$. The influence of sleep deprivation and oscillating motion on sleepiness, motion sickness, and cognitive and motor performance. Auton Neurosci. 2017;202:86-96, https://doi.org/10.1016/j.autneu.2016.08.019.

9. Koca C, Bayindir T. [Review of pathophysiology, epidemiology, diagnosis and treatment methods in motion sickness; a special issue]. J Turgut Ozal Med Cent. 2017;24(3):365-70, https://doi.org/10.5455/jtomc.2016.08.092. Turkish.

10. Sharon JD, Hullar TE. Motion sensitivity and caloric responsiveness in vestibular migraine and Ménière's disease. Laryngoscope. 2014;124(4):969-73, https://doi.org/10.1002/ lary.24285.

11. Diamond SG, Markham CH. Validating the hypothesis of otolith asymmetry as a cause of space motion sickness. Ann N Y Acad Sci. 1992;656:725-31.

12. Bles W, Bos JE, de Graaf B, Groen E, Wertheim AH. Motion sickness: only one provocative conflict? Brain Res Bull. 1998;47(5):481-7.

13. Yates BJ, Holmes MJ, Jian BJ. Adaptive plasticity in vestibular influences on cardiovascular control. Brain Res Bull. 2000;53(1):3-9.
14. Holmes SR, Griffin MJ. Correlation Between Heart Rate and the Severity of Motion Sickness Caused by Optokinetic Stimulation. J Psychophysiol. 2001;15(1):35-42, https://doi. org/10.1027//0269-8803.15.1.35.

15. Matsangas P, McCauley ME, Becker W. The effect of mild motion sickness and sopite syndrome on multitasking cognitive performance. Hum Factors. 2014;56(6):1124-35, https:// doi.org/10.1177/0018720814522484.

16. Powell-Dunford N, Bushby A. Management of Sea Sickness in Susceptible Flight Crews. Mil Med. 2017;182(11):e184650, https://doi.org/10.7205/MILMED-D-17-00029.

17. Nachum Z, Shupak A, Gordon CR. Transdermal Scopolamine for Prevention of Motion Sickness. Clin Pharmacokinet. 2006;45(6):543-66, https://doi.org/10.2165/00003088200645060-00001.

18. Gordon CR, Gonen A, Nachum Z, Doweck I, Spitzer O, Shupak A. The effects of dimenhydrinate, cinnarizine and transdermal scopolamine on performance. J Psychopharmacol. 2001;15(3):167-72, https://doi.org/10.1177/02698811010 1500311.

19. Eden D, Zuk Y. Seasickness as a self-fulfilling prophecy: raising self-efficacy to boost performance at sea. J Appl Psychol. 1995;80(5):628-35.

20. Golding JF. Motion sickness susceptibility questionnaire revised and its relationship to other forms of sickness. Brain Res Bull. 1998;47(5):507-16.

21. Aitken RC. Measurement of feelings using visual analogue scales. Proc R Soc Med. 1969;62(10):989-93.

22. Folstein MF, Luria R. Reliability, validity, and clinical application of the Visual Analogue Mood Scale. Psychol Med. 1973;3(4):479-86.

23. Gianaros PJ, Muth ER, Mordkoff JT, Levine ME, Stern RM. A questionnaire for the assessment of the multiple dimensions of motion sickness. Aviat Space Environ Med. 2001; 72(2):115-9.

24. Yates BJ, Aoki M, Burchill P, Bronstein AM, Gresty MA. Cardiovascular responses elicited by linear acceleration in humans. Exp Brain Res. 1999;125(4):476-84. 
25. Ndayisaba J-P, Fanciulli A, Granata R, Duerr S, Hintringer F, Goebel G, et al. Sex and age effects on cardiovascular autonomic function in healthy adults. Clin Auton Res. 2015;25(5):317-26, https://doi.org/10.1007/s10286-015-0310-1.

26. Magnani S, Mulliri G, Sainas G, Ghiani G, Pinna V, Sanna I, et al. Occurrence of cardiac output decrease (via stroke volume) is more pronounced in women than in men during prolonged dry static apnea. J Appl Physiol. 2018;124(2):349-55, https://doi.org/10.1152/japplphysiol.00991.2016.

27. Kangas P, Tahvanainen A, Tikkakoski A, Koskela J, Uitto M, Viik J, et al. Increased cardiac workload in the upright posture in men: Noninvasive hemodynamics in men versus women. J Am Heart Assoc. 2016;5(6):1-13, https://doi.org/ 10.1161/JAHA.115.002883.

28. Prodel E, Barbosa TC, Nóbrega AC, Vianna LC. Cardiovascular response to trigeminal nerve stimulation at rest and during exercise in humans: does sex matter? Am J Physiol Regul Integr Comp Physiol. 2018;315(1):R68-75, https://doi. org/10.1152/ajpregu.00406.2017.

29. Wilhelm FH, Rattel JA, Wegerer M, Liedlgruber M, Schweighofer S, Kreibig SD, et al. Attend or defend? Sex differences in behavioral, autonomic, and respiratory response patterns to emotion-eliciting films. Biol Psychol. 2017;130:3040, https://doi.org/10.1016/j.biopsycho.2017.10.006.

30. Stolarz K, Staessen JA, Kuznetsova T, Tikhonoff V, State D, Babeanu S, et al. Host and environmental determinants of heart rate and heart rate variability in four European populations. J Hypertens. 2003;21(3):525-35, https://doi.org/ 10.1097/00004872-200303000-00018.

31. Dutra SG V, Pereira APM, Tezini GCS V, Mazon JH, MartinsPinge MC, Souza HCD. Cardiac autonomic modulation is determined by gender and is independent of aerobic physical capacity in healthy subjects. PLoS One. 2013;8(10):e77092, https://doi.org/10.1371/journal.pone.0077092.

32. Javaid A, Chouhna H, Varghese B, Hammam E, Macefield VG. Changes in skin blood flow, respiration and blood pressure in participants reporting motion sickness during sinusoidal galvanic vestibular stimulation. Exp Physiol. 2019;0:1-23, https://doi.org/10.1113/ep087385.

33. Sufrinko AM, Kegel NE, Mucha A, Collins MW, Kontos AP. History of High Motion Sickness Susceptibility Predicts Vestibular Dysfunction Following Sport/Recreation-Related Concussion. Clin J Sport Med. 2017;0:1-6, https://doi.org/10. 1097/JSM.0000000000000528.

34. Graybiel A, Knepton J. Sopite syndrome: a sometimes sole manifestation of motion sickness. Aviat Space Environ Med. 1976;47(8):873-82.

35. Nelesen R, Dar Y, Thomas K, Dimsdale JE. The relationship between fatigue and cardiac functioning. Arch Intern Med. 2008;168(9):943-9, https://doi.org/10.1001/archinte.168.9.943.

36. Duschek S, Hoffmann A, Reyes del Paso GA. Affective impairment in chronic low blood pressure. J Psychosom Res. 2017;93:33-40, https://doi.org/10.1016/j.jpsychores.2016. 12.008 .

This work is available in Open Access model and licensed under a Creative Commons Attribution-NonCommercial 3.0 Poland License - http://creativecommons.org/ licenses/by-nc/3.0/pl/deed.en. 